\title{
IN MEMORY OF PROFESSOR DAVID KRINSLEY, UNIVERSITY OF OREGON
}

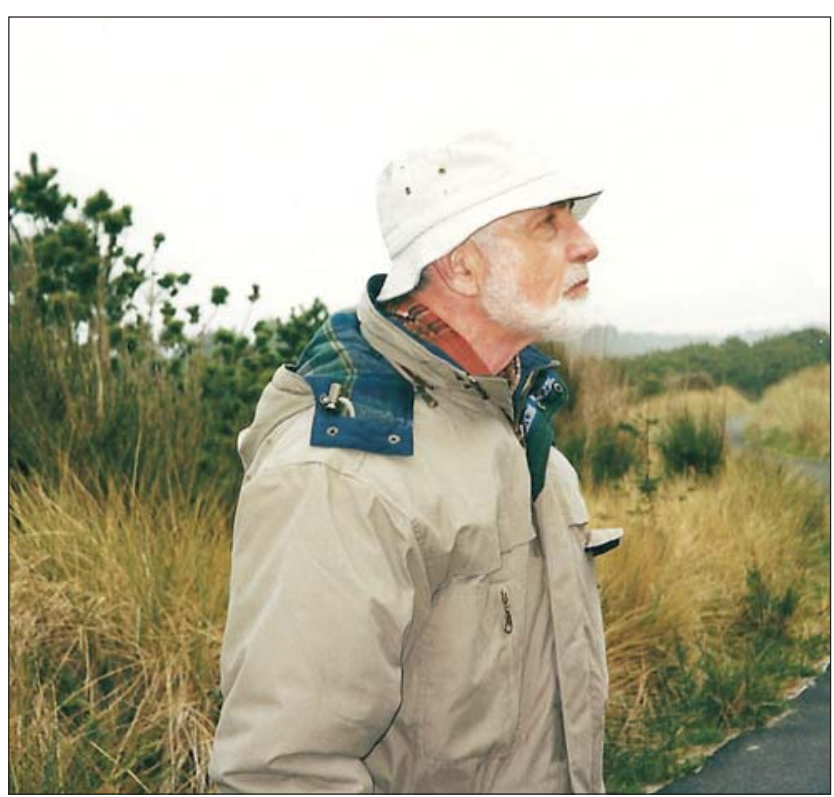

Dave Henry Krinsley, colleague of many professionals and mentor to countless students over several decades, a man possessed of enormous scientific talent and ability, died quietly in his sleep on November 5, 2017, age 90. He had a long history at the University of Chicago, Cambridge University (UK), Queens (NY), Arizona State University (Tempe), finishing his days at the Department of Geological Sciences, University of Oregon and the laboratories of CAMCOR (Eugene).

Beginning in the 1960's Dave teamed up with others (Krinsley and Takahashi, 1962) to open the electron microscope to the analysis of sand grain textures as signatures of various environments, including experimental work on links between aeolian environments, and inherited surface microtextures on quartz sand. His later work with John Doornkamp (1973) at Nottingham resulted in the Atlas of Sand Grain Surface Textures, the first inventory of its kind that sparked a flurry of testing by Dave and others. This trial run period led to the principle of equifinality, that is, that some microtextures could be produced in multiple environments, so that only a few rare microtextures were endemic to just one environment. Subsequent work showed that multiple overprintings revealed vestiges of preweathering followed by several overprintings, relative ages judged on the basis of differential weathering of grain imprintings.
While concentrating on aeolian signatures and lab experimentation, Dave moved from SE to BSE electron microscopy, on to TEM, STEM and FIB analyses, and to simulations of aeolian processes and expected grain microfeatures to be identified at some point on Mars (Krinsley et al., 1979). Add to this, Dave's contribution of SEM microtexture grain analysis of different lithologies in sedimentary rocks of marine and terrestrial origin, and extended through time to the Precambrian, showed investigators how the electron microscope could shed light on geologic processes and environmental reconstruction through the vast expanse of geologic time. One of his latest papers, published in Scanning (Mahaney et al., 2016), demonstrated how combinations of STEM and FIB methods could be applied to weathering rinds, the combined analyses allowing microstratigraphic imaging and chemical analyses with depth, all shedding light on the black mat event as it affected the Western Alps $12.8 \mathrm{ka}$. His participation in the discovery of airburst related sediment, possibly black mat equivalent minerals in Antarctic paleosols, continued unabated right up to his passing.

Dave is remembered also for his numerous papers on desert varnish, many done in conjunction with Ron Dorn at Tempe. Aside from his drive to understand geological processes and paleoenvironments, he is remembered as a man imbued with limitless curiosity that kept him in the lab right up to the end of his life. His associates at Arizona and Oregon remember him as an intellectual source that will be hard to replace and one from which they enjoyed some heady times of discovery.

Bill Mahaney, York University and Quaternary Surveys, Toronto, Canada.

Kurt Langworthy and Robert Fischer, University of Oregon, CAMCOR, Eugene, Oregon, USA.

Ron Dorn, Arizona State University, Tempe, USA.

\section{References}

Krinsley, D.H, Takahashi, T., 1962. The surface textures of sand grains: an application of electron microscopy. Science, 135, 923-925.

Krinsley, D., Greeley, R., Pollack, J., 1979. Abrasion of wind-blown particles on Mars-erosion of quartz and basaltic sand under simulated martian conditions. Icarus 39, 364-384.

Mahaney, W.C., Krinsley, D.H., Fischer, R., Langworthy, K., 2016. Clast rind analysis using multi-high resolution scanning instrumentation, Scanning, 38 (3), 202-212.

Krinsley, D.H., Doornkamp, J., 1973. Atlas of Sand Grain Surface Textures. Cambridge, the University Press, 91 pp. 